Access this article online

Website:

onbt.scholasticahq.com

DOI:

10.18639/ONBT.2016.03.1256

\section{Radiotherapy-induced depigmentation in breast cancer patients without prior history of vitiligo: A review}

\author{
Roshankumar A Patil, Tabassum A Wadasadawala
}

\title{
Abstract:
}

Background: Vitiligo is a relatively common pigment disorder. Exacerbation or complete depigmentation within the radiation portals as a result of the Koebner phenomenon in patients with preexisting vitiligo has been reported in the literature. However, new-onset vitiligo triggered by radiation in patients without prior history of the disorder is a rare occurrence. Methods: The authors report one such occurrence in a breast cancer patient wherein the depigmentation remained localised within the radiotherapy target volume without generalisation. This young lady had received adjuvant radiotherapy to the right breast and ipsilateral supraclavicular fossa to a dose of 50 Gy in 25 fractions followed by 15 Gy in 6 fractions to the tumour bed. Discussion: The authors present a short review of the literature and discussion on the etiopathogenesis and therapeutic implication of the condition in cancer management. Conclusion: This rare occurrence highlights the importance of taking decision on radiotherapy on a case-to-case basis in patients known to have vitiligo as it has direct bearing on the ultimate cosmetic and psychological outcome. However, it is also equally important to be aware that radiation-induced depigmentation be a precursor of subsequent new-onset generalised vitiligo.

Key words:

Radiotherapy, breast carcinoma, vitiligo

Key Messages:

What's known: Reports of radiation therapy leading to depigmentation in a known case of vitiligo.

What's new: Only a handful of cases reported de novo, that is, without prior history of vitiligo. Oncologist should be aware of this phenomenon and make an appropriate therapeutic decision.

\section{Introduction}

Radiation Oncology,

Advanced Centre for

Treatment, Research

and Education in

Cancer (ACTREC),

Tata Memorial

Centre, Mumbai,

Maharashtra, India

Address for correspondence:

Tabassum A

Wadasadawala,

Department of Radiation

Oncology, PS 259,

Advanced Centre for

Treatment, Research

and Education in

Cancer (ACTREC), Tata

Memorial Centre, Mumbai,

Maharashtra, India.

twadasadawala@actrec.gov.in

Phone No.: +91-22-27405079

Submission: 05-09-16

Accepted: 02-11-16
$\mathrm{V}^{\mathrm{i}}$ itiligo is a relatively commonly acquired disorder of pigmentation characterized by the development of well-defined white macules on the skin. Estimated prevalence rates range from 0.1 to $2 \%$ in both adults and children. ${ }^{[1]}$ Biopsy of the skin lesion reveals a loss of epidermal melanocytes. It has a profound impact on the quality of life of both adult and paediatric patients, especially in the dark skinned. ${ }^{[2]}$ The underlying aetiology of vitiligo is multifactorial. Patients commonly attribute the onset of their disease to specific triggering events such as physical injury or illness, sunburn, emotional stress, or pregnancy, but there is no data supporting a causative role for these factors. The underlying cause can be genetic, biochemical, immunological, or autoimmunity. ${ }^{[3]}$ Radiation-induced melanocyte loss has been described in the literature in patients with preexisting vitiligo, which manifests as patches of vitiligo within the radiation portal. However, new-onset vitiligo triggered by radiation in patients without prior history of the disorder is a rare occurrence. We present a similar case of breast cancer that developed depigmentation within the confines of radiation portals two months post radiotherapy. This is the fifth such case in breast cancer that the authors report and seventh one across all sites. We also discuss the various hypotheses proposed for vitiligo and review all the cases reported in the literature.

\section{Case History}

A 40-year-old lady with no significant medical or family history presented with a lump of 6 months duration in her right breast, measuring

This is an open access article distributed under the terms of the Creative Commons Attribution-NonCommercial-ShareAlike 3.0 License, which allows others to remix, tweak, and build upon the work non-commercially, as long as the author is credited and the new creations are licensed under the identical terms

How to cite this article: Patil RA, Wadasadawala TA. Radiotherapy-induced depigmentation in breast cancer patients without prior history of vitiligo: A review. Oncobiol Targets 2016;3:9. 
$4 \mathrm{~cm}$ in greatest dimension, along with a mobile palpable ipsilateral axillary lymph node $1.5 \mathrm{~cm}$ in size. It was confirmed to be invasive ductal carcinoma, which was $\mathrm{ER}+/ \mathrm{PR}+/ \mathrm{HER} 2 \mathrm{neu}+$ on immunohistochemistry. The patient received neo-adjuvant chemotherapy consisting of four cycles of cyclophosphamide, adriamycin and 5 fluorouracil, following which she underwent breast conservation surgery. Histopathological examination of the specimen confirmed pathological complete response and was staged as ypT0ypN0M0. She received two more cycles of the same chemotherapy regimen in the adjuvant setting in view of good response.

Subsequently, she received external beam radiotherapy to the right breast and supraclavicular fossa (SCF) to a dose of 50 Gy in 25 fractions using six MV photon beams with the threedimensional conformal radiotherapy technique followed by a boost to the tumour bed to a dose of $15 \mathrm{~Gy}$ in 6 fractions from 15 September, 2014, to 20 October, 2014. Radiation dermatitis in the form of hyperpigmentation and dry desquamation, involving the entire treated breast, was noticed at the time of radiotherapy conclusion. Her skin reactions resolved within two weeks. Approximately two months after the completion of radiation, the patient noticed well-defined depigmented lesions on her right breast, which were patchy to begin with and gradually increased in size over subsequent two weeks to become congruent. The depigmentation was located within the confines of radiotherapy tangential portals as shown by arrows in Figure 1. The clinical photograph was taken after obtaining verbal consent from the patient as well as her relative, assuring confidentiality.

She had no pruritus or pain but gave history of excessive sweating. No depigmentation was noticed in the low neck region where SCF was irradiated. On retrospect interrogation, previous history or family history of vitiligo was not confirmed. Similarly, retrospect general examination revealed only a small hypopigmented area on the medial aspect of her left wrist, which was old burn sequelae, and on the back of right midthigh, which had occurred during chemotherapy

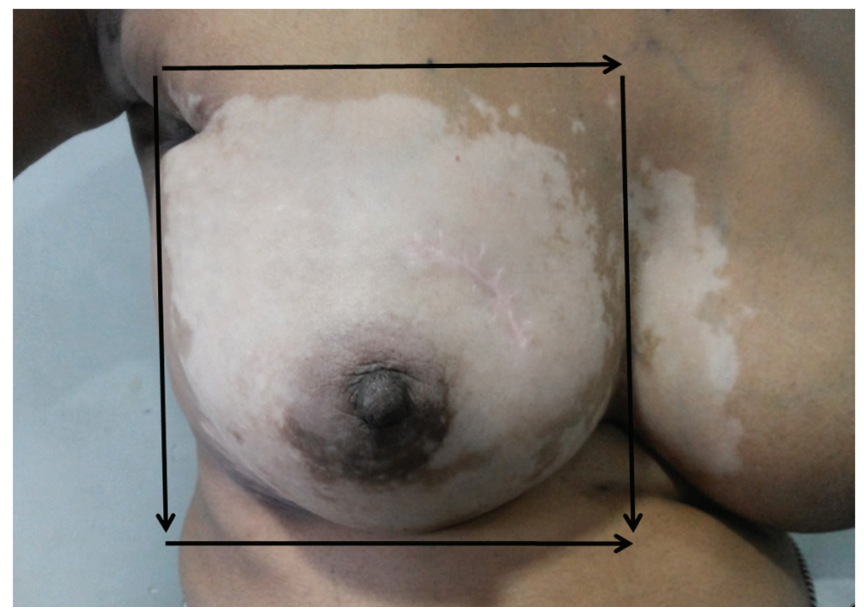

Figure 1: Clinical photograph showing confluent depigmentation of the skin over the right breast within the confines of radiation portals as illustrated with the help of arrows in June 2014. There was no hypo- or depigmentation of the breast before the commencement of radiation. The depigmented area over the breast had well-defined margins clearly demarcating the treated area. They had coalesced and persisted till the time this case was reported. There was no progression of the depigmentation to other parts of the body.

\section{Discussion}

Vitiligo is a pigment disorder characterized by patchy or generalised depigmented patches, affecting the skin and mucous membrane. It starts with the affection of sunexposed areas, that is, extremities and face, favouring orificial distribution. It is clinically classified into localised, generalised and universal subtypes depending upon the extent of depigmented skin or mucosa. The exact etiopathogenesis of vitiligo is not known with a dozen of theories being proposed for the same.

There are many hypotheses proposed for vitiligo like melanocyte self-destruction hypothesis, oxidative stress hypothesis, neural hypothesis and melanocytorrhagy hypothesis. ${ }^{[4-7]}$ Despite extensive basic research, no conclusive proof exists to demonstrate how exactly epidermal melanocytes are actually killed by the proposed cytotoxic agent or mechanism. Hence Schallreuter et al. have proposed a new "convergence theory" suggesting a multifactorial and a multistep etiopathogenesis. ${ }^{[3]}$ The common denominator of this condition, irrespective of the offending agent, is melanocyte depletion. The exact mechanism of radiationinduced apoptosis of the melanocytes mainly related to the free radical damage has been elucidated by the previous authors reporting such cases. However, the mechanism of generalisation (second hit) of depigmentation following the local pigmentation (first hit) appears to be related to the autoimmune response with or without genetic predisposition. Vitiligo induced by radiation therapy as a result of the Koebner phenomenon in a known case has been reported in the literature. The authors could collect four such cases but they have not been included in Table 1 as it is a well-known and established phenomenon. Table 1 summarises the cases who presented as new-onset vitiligo induced by radiation. Of the seven cases of new-onset vitiligo, five have been reported for breast cancer with nasopharynx and mediastinum being the other sites. ${ }^{[8-13]}$ Generalisation of the disorder has been reported by only two authors. Probably longer follow-up of the cases reported by other authors could help understand the phenomenon better. Similar to the case reported earlier from our institute, depigmentation developed in the area irradiated by the tangential portals and not in the skin irradiated by the supraclavicular portal. The physical basis of this observation has also been reported earlier.

\section{Conclusion}

Only a handful of cases of new-onset vitiligo following radiotherapy has been reported till date. This rare occurrence highlights the importance of taking decision on radiotherapy on a case-to-case basis in patients known to have vitiligo as it has direct bearing on the ultimate cosmetic and psychological 
Table 1: Case reports of radiation-induced depigmentation in patients without history of prior vitiligo

\begin{tabular}{|c|c|c|c|c|c|c|c|c|c|}
\hline Author (ref) & N/Site & $\begin{array}{l}\text { Chemotherapy } \\
\text { agents }\end{array}$ & RT dose & $\begin{array}{c}\text { Time } \\
\text { interval }\end{array}$ & $\begin{array}{c}\text { Generalisation } \\
\text { with interval }\end{array}$ & $\begin{array}{l}\text { n FU post } \\
\text { RT }\end{array}$ & $\begin{array}{l}\text { Timing } \\
\text { of RT }\end{array}$ & Target volume & $\begin{array}{c}\text { Location of } \\
\text { depigmentation }\end{array}$ \\
\hline Polat et al. ${ }^{[2]}$ & 1/NPhx & Cisplatin & $\begin{array}{l}32 \mathrm{~Gy} / 16 \\
\text { fractions }\end{array}$ & 2 months & None & 2 years & Concurrent & Neck-Face & Neck-Face \\
\hline Munshi et al. ${ }^{[3]}$ & 1/Breast & A based & $\begin{array}{l}45 \mathrm{~Gy} / 20 \\
\text { fractions }\end{array}$ & 6 months & None & 6 months & Adjuvant & Chest wall + SCF & Chest wall only \\
\hline Kim et al. ${ }^{[4]}$ & 1/Thymoma & None & $\begin{array}{l}55 \text { Gy/31 } \\
\text { fractions }\end{array}$ & 3 months & None & 3 months & Adjuvant & Chest & Anterior chest \\
\hline Pavithran et al..$^{[5]}$ & 1/Breast & A-T based & $\begin{array}{l}50 \text { Gy/25 } \\
\text { fractions }\end{array}$ & 9 months & None & 2 years & Adjuvant & Chest wall & Chest wall \\
\hline Vajrala et al. ${ }^{[6]}$ & 1/Breast & A-T based & $\begin{array}{l}46 \text { Gy/23 } \\
\text { fractions }\end{array}$ & 9 months & Immediate & 9 months & Adjuvant & $\begin{array}{c}\text { Chest } \\
\text { wall }+ \text { SCF }+A X+I M N\end{array}$ & Generalised \\
\hline Biswas et al..$^{[7]}$ & 2/Breast & $\begin{array}{l}\text { A-T based } \\
\text { and CMF }\end{array}$ & $\begin{array}{l}50 \text { Gy/25 } \\
\text { fractions }\end{array}$ & 1-3 months & $\begin{array}{l}\text { Immediate }-4 \\
\text { months }\end{array}$ & 12 years & Adjuvant & Breast $+\mathrm{SCF}+\mathrm{AX}$ & Generalised \\
\hline Present case & 1/Breast & A-T based & $\begin{array}{l}50 \mathrm{~Gy} / 25 \\
\text { fractions }\end{array}$ & 2 months & $\begin{array}{l}\text { Within 2-3 } \\
\text { months }\end{array}$ & 6 months & Adjuvant & Breast + SCF & Generalised \\
\hline
\end{tabular}

RT: Radiotherapy, FU: Follow-up, A: Anthracycline, T: Taxanes, NPhx: Nasopharynx, SCF: Supraclavicular fossa, AX: Axilla, IMN: Internal mammary nodes, CMF: Cyclophosphamide, methotrexate, 5-fluorouracil.

outcome. ${ }^{[2]}$ However, it is also equally important to be aware that radiation-induced depigmentation in patients without prior history of vitiligo may be a precursor of subsequent generalised vitiligo. The patient affected with vitiligo should be clearly counselled about the risk of complete pigment loss following radiation therapy. This should be discussed prior to start of definitive treatment as the patient may opt for alternative treatment that may not involve radiotherapy (mastectomy instead of breast conservation) or involve different forms of radiotherapy (e.g. brachytherapy) that may lead to less skin dose and melanocyte loss.

\section{Source(s) of support}

None.

Presentation at a meeting

Maharashtra chapter of AROI on 13 August 2016 in Kolhapur, India.

\section{Conflicting interest}

None.

Patient consent statement

Informed consent was obtained from the patient prior to the study.

\section{References}

1. Yaghoobi R, Omidian M, Bagherani N. Vitiligo: A review of the published work. J Dermatol 2011;38:419.

2. Krüger C, Schallreuter KU. Stigmatisation, avoidance behaviour and difficulties in coping are common among adult patients with vitiligo. Acta Derm Venereol 2015;95:553.

3. Schallreuter KU, Bahadoran P, Picardo M, Slominski A, Elassiuty YE, Kemp EH, et al. Vitiligo pathogenesis: Autoimmune disease, genetic defect, excessive reactive oxygen species, calcium imbalance, or what else? Exp Dermatol 2008;17:139-60.

4. Taieb A, Alomar A, Böhm M, Dell'anna ML, De Pase A, Eleftheriadou $\mathrm{V}$, et al. Guidelines for the management of vitiligo: The European Dermatology Forum consensus. Br J Dermatol 2013;168:5.

5. Dell'Anna ML, Maresca V, Briganti S, Camera E, Falchi M, Picardo M. Mitochondrial impairment in peripheral blood mononuclear cells during the active phase of vitiligo. J Invest Dermatol 2001;117:908

6. Njoo MD, Westerhof W. Vitiligo. Pathogenesis and treatment. Am J Clin Dermatol 2001;2:167.

7. Gauthier Y, Cario-Andre M, Lepreux S, Pain C, Taïeb A. Melanocyte detachment after skin friction in non lesional skin of patients with generalized vitiligo. Br J Dermatol 2003; 148:95.

8. Vajrala G, Jain PK, Surana S, Fernandes DJ. Generalized vitiligo post radiotherapy in a breast cancer patient. J Cancer Res Ther 2014 Apr-Jun;10(2):365-7.

9. Biswas A, Chaudhari PB, Julka PK, Rath GK. Radiation induced depigmentation disorder in two patients with breast cancer: Exploring a rare accompaniment. J Egypt Natl Canc Inst 2015 Feb 20. pii:S1110-0362(15)00005-9.

10. Kim DH, Kim CW, Kim TY. Vitiligo at the site of radiotherapy for malignant thymoma. Acta Derm Venereol 1999 Nov; 79(6):497.

11. Munshi A, Jain S, Budrukkar A, Jalali R, Sarin R. Radiotherapyinduced depigmentation in a patient with breast cancer. Indian J Cancer 2007 Oct-Dec;44(4):157-8.

12. Polat M, Yalçin B, Alli N. Vitiligo at the site of radiotherapy for nasopharyngeal carcinoma. Am J Clin Dermatol 2007;8(4): 247-9.

13. Pavithran K, Pande SB, Dinesh M. Report of a case of radiationinduced new-onset vitiligo with collective review of cases in the literature of radiation-related vitiligo. Case Rep Med 2013;2013:Article ID:345473. 